\title{
Synthesis of some Acetylenic Amino Derivatives from Salicylic Acid
}

\author{
Zenab F. Saeed \\ Veterinary Medicine College \\ University of Mosul
}

Received

23 / 03 / 2009
Accepted

03 / 06 / 2009

\section{الخلاصة}

حضرت مشقلت جيية لأمينات لستيلينية حاوية على مجموعة للسللسليت من خ لال

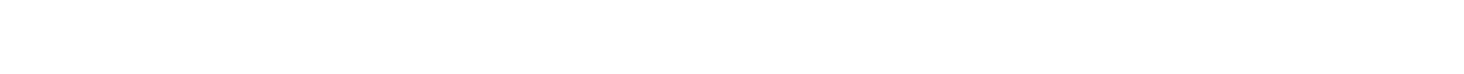
وقم إثبا الصبغ التركيبية للمركبت المحضرة بلستخدالم الطاررايق الفيزياوية والطفية.

\begin{abstract}
New derivatives of acetylenic amines containing salicylate group have been synthesized through Mannich reaction which involved reaction of propargyl salicylate with paraformaldehyde and secondary amines. The structural formula of the synthesized compounds have been investigated by physical and spectroscopic methods.
\end{abstract}

\section{INTRODUCTION}

Many types of Mannich reaction have been used in the organic synthesis, the first one at (1912) involved amino alkylation of $\alpha-\mathrm{CH}-$ acidic compounds ( $\alpha$-methylene carbonyls) with formaldehyde and ammonia or any primary or secondary amine to yield $\beta$-amino carbonyl compounds (Mannich bases) [1].

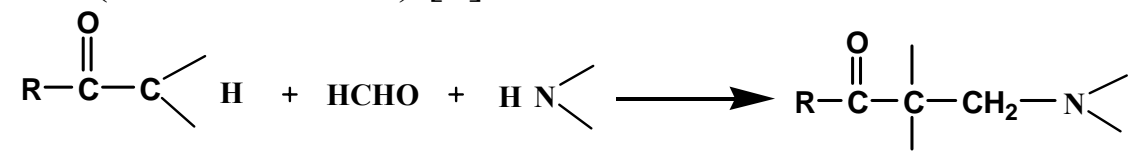

Other $\alpha$-acidic compounds are acetylenic compounds used in Mannich reaction in presence of $\mathrm{CuCl}$ as a catalyst to give acetylenic amino compounds [2]. 


$$
\mathrm{R}-\mathrm{CH}_{2}-\mathrm{C} \equiv \mathrm{C}-\mathrm{H}+\mathrm{HCHO}+\mathrm{HN} \longrightarrow \stackrel{\mathrm{CuCL}}{\longrightarrow}-\mathrm{R}_{2}-\mathrm{C} \equiv \mathrm{C}-\mathrm{CH}_{2}-\mathrm{N}
$$

The yield of Mannich product was increased on using highly effective catalysts (gold salts) such as $\mathrm{AuCl}, \mathrm{AuI}, \mathrm{AuCl}_{3}$, and $\mathrm{AuBr}_{3} . \mathrm{As}$ $\mathrm{AuBr}_{3}$ the last one is relatively cheaper among these gold salts and the most effective, it was therefore chosen as the prefered catalyst with the concentration of $\left(0.25 \mathrm{~mol} \mathrm{AuBr}_{3}\right)$ to give $98 \%$ yield [3].

Another type of Mannich reaction used $\alpha-\mathrm{NH}$-acidic compounds such as 5-alkyl-1,3,4-oxadiazol -2 $(3 \mathrm{H})$ - thione without catalyst to give new type of Mannich products [4].

The Mannich products (acetylenic amine derivatives) were considered pharmaceutically active compounds for possessing several biological activities such as antispasmodics [5], hypertensive agents [6], anticholinergic agents for reducig the effect of acetyl choline in living organism [7], treatment of Parkinson's disease [8], also some of acetylenic amines were used as thymidylate synthase inhibitors [9], anticancer agents [10], oxotremorine antagonists [11], and antibacterial agents [12].

\section{EXPERIMENTAL}

Melting points were measured on an electrothermal 1A 9000 Digital -series apparatus and are uncorrected. IR spectra were recorded by Infrared Spectrophotometer FTIR-Tensor 27-Bruker as KBr disc. UV spectra were measured by Shimadzu UV-Visible Spectrophotometer UV160 using absolute EtOH.

\section{Methods of preparation}

Preparation of sodium salicylate (1) [12C]:

Salicylic acid (0.02 mole) was dissolved in an aqueous solution of sodium bicarbonate $(0.02 \mathrm{~mole})$ in water $(20 \mathrm{ml})$. The solution was evaporated to dryness to obtain a white powder of sodium salicylate.

\section{Preparation of propargyl salicylate (2) [12C]:}

Propargyl bromide ( 0.02 mole) was added to a solution of sodium salicylate $(0.02 \mathrm{~mole})$ in water $(20 \mathrm{ml})$. The mixture was heated on water bath at $\left(70-80{ }^{\circ} \mathrm{C}\right)$ for $2 \mathrm{hrs}$ with stirring. After cooling, cold water (40 $\mathrm{ml}$ ) was added with stirring till the oily product was changed to solid precipitate. The precipitate was filtered, washed with cold water and dried, then recrystallized from benzene to obtain a brown crystals of $68 \%$ yield and m.p. $\left(50-52{ }^{\circ} \mathrm{C}\right)$. The spectral data of compound (2) showed the following characteristic absorption bands:

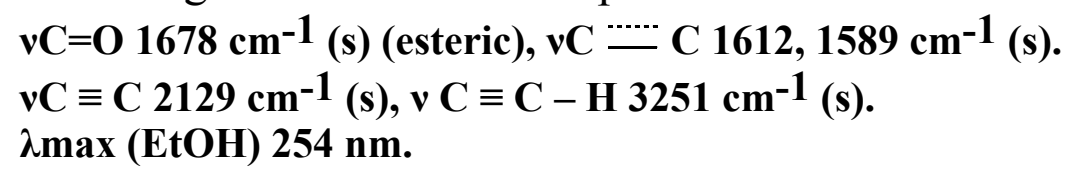




\section{Preparation of 4-Amino -2- butynyl salicylate Derivatives (3a-h) :}

General method (Mannich reaction) [2] :

Acetylenic compound ( 0.03 mole) was mixed with secondary amine $(0.036$ mole $)$ in a round bottom flask fitted with condenser. The mixture was cooled to $0{ }^{\circ} \mathrm{C}$ in an ice bath, then paraformaldehyde $(0.036$ mole $)$ and $\mathrm{CuCl}(0.06 \mathrm{gm})$ in peroxide -free dioxane $(20 \mathrm{ml})$ were added. The reaction mixture was cooled again to $0{ }^{\circ} \mathrm{C}$ and glacial acetic acid (4.5 $\mathrm{ml}$ ) was added dropwise with shaking. The mixture was stirred at room temperature for 5 minutes then at $90^{\circ} \mathrm{C}$ for $2 \mathrm{hrs}$.

After cooling, water $(60 \mathrm{ml})$ was added and the reaction mixture was acidified to $(\mathrm{pH}=1)$ by dropwise addition of $1: 1\left(\mathrm{HCl}: \mathrm{H}_{2} \mathrm{O}\right)$ with stirring then extracted with $(2 \times 50 \mathrm{ml})$ of ether The aqueous phase was made alkaline with saturated solution of sodium bicarbonate. The precipitate was filtered, washed several times with water, then dried and recrystallized from benzene - pet. spirit $\left(80-100{ }^{\circ} \mathrm{C}\right)$ to obtain the desired products (3a-h). The physical and spectral data are listed in Table (1).

\section{RESULTS AND DISCUSSION}

Previous studies showed that many acetylenic amines derivatives were found to be pharmaceutical active compounds [5-12]. Accordingly, some new acetylenic amines derivatives containing salicylate group have been synthesized. The aim of using such group (salyicylate) in the skeleton structure of the acetylenic amines may improve the biological activity of these compounds. Therefore, new acetylenic amines derivatives (3a-h) have been synthesized through Mannich reaction as shown in scheme (1).

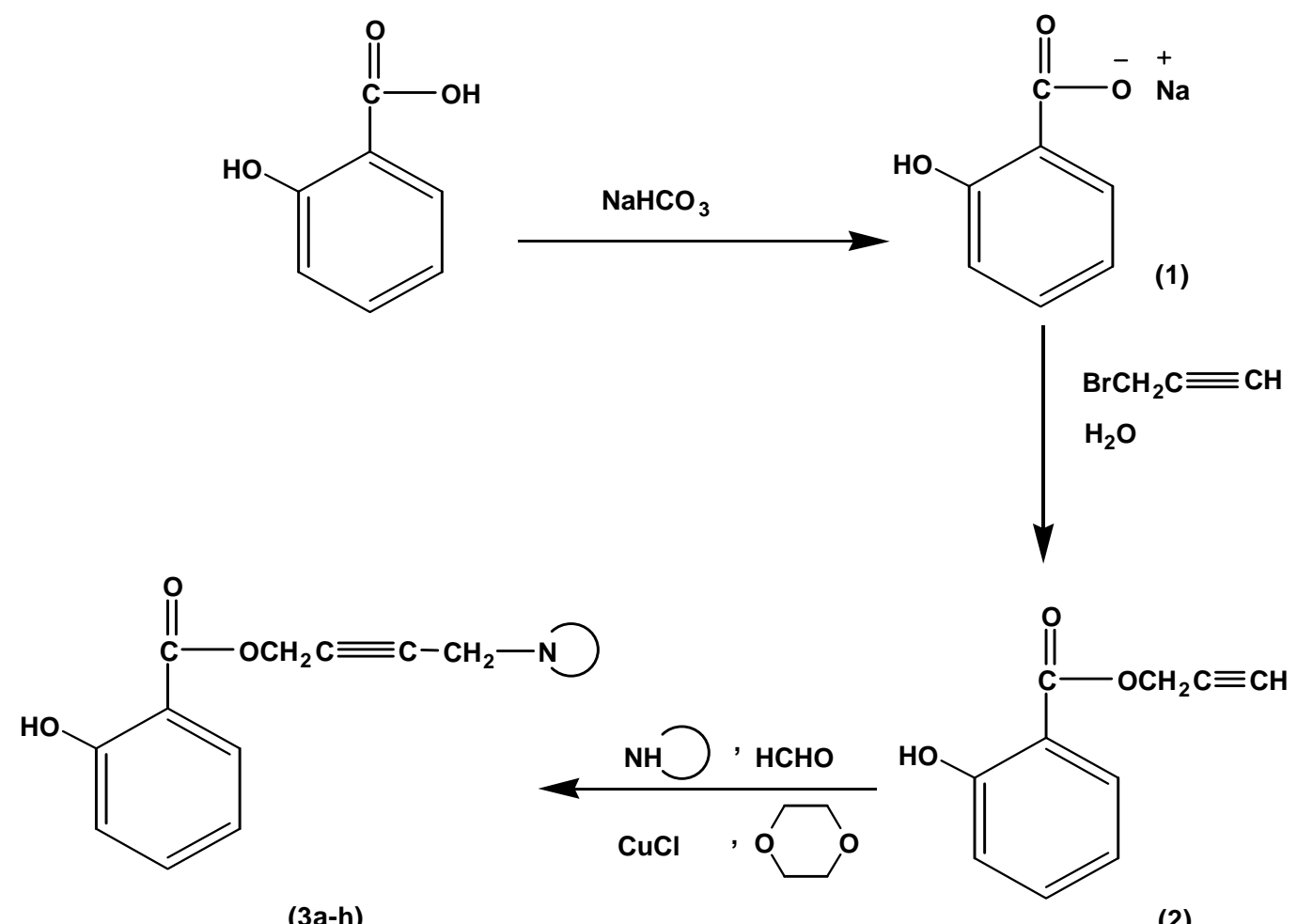

(3a-h)

(2) 


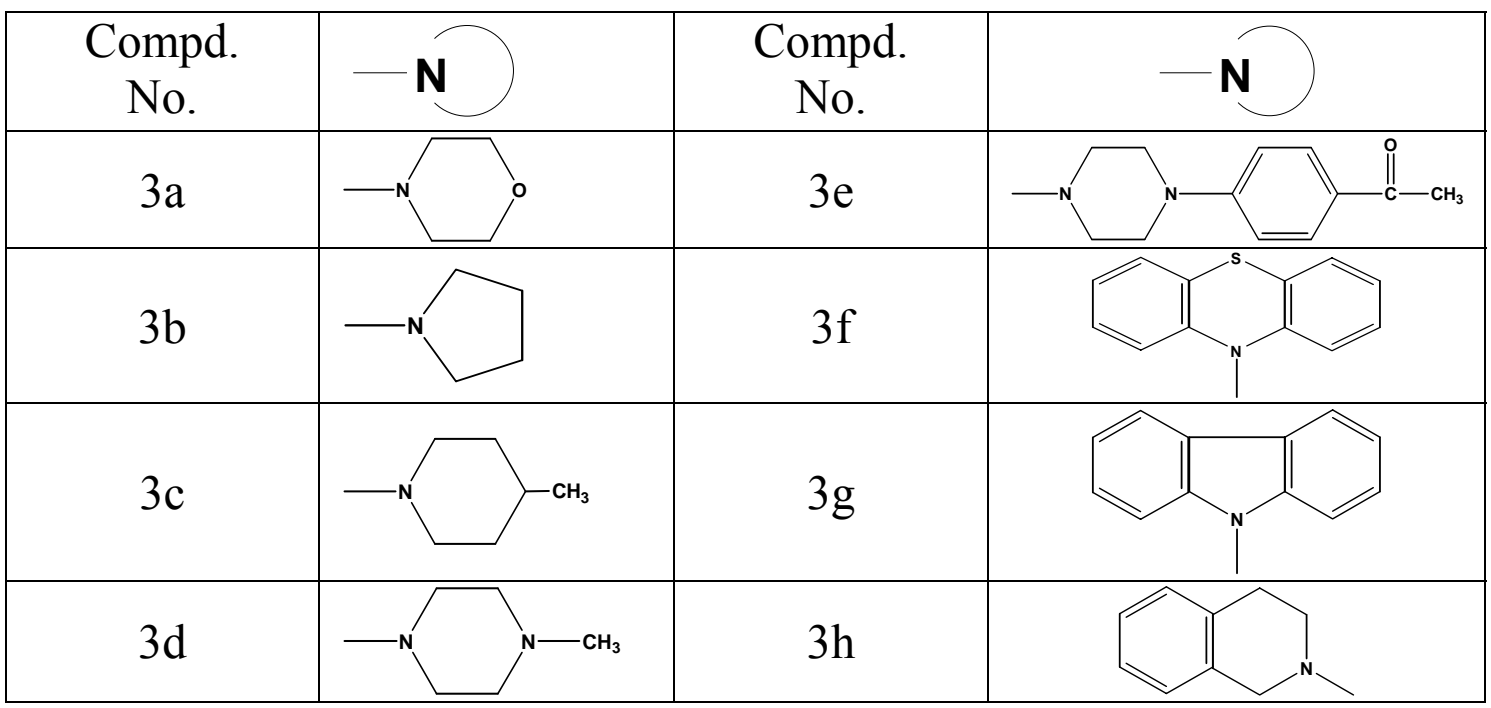

Scheme (1)

The structural investigation of the synthesized acetylenic amines derivatives (3a-h) was achieved according to their physical and spectroscopic data (IR, UV) [13], Other supporting evidences is that the acetylenic hydrogen in compound (2) showed positive Tollen test which become negative test in Mannich products (3a-h), also the latter compounds showed the presence of phenolic group through the positive ferric chloride test [14].

IR spectra of compounds (3a-h) as indicated in Table (1) showed strong absorption bands for esteric $\mathrm{C}=\mathrm{O}$ at lower frequencies $(1678-$ 1693 $\mathrm{cm}^{-1}$, this is due to the conjugation effect and intramolecular hydrogen bonding effect in these compounds, two absorption bands for the skeleton vibrations of aromatic ring at $(1516-1615) \mathrm{cm}^{-1}$, weak band for $\mathrm{C} \equiv \mathrm{C}$ at $(2121-2154) \mathrm{cm}^{-1}$, also showed broad band for $\mathrm{O}-\mathrm{H}$ at (3382-3434) $\mathrm{cm}^{-1}$. Moreover, the IR spectra indicated the disappearance of $\equiv \mathrm{C}-\mathrm{H}$ in Mannich products (3a-h) as compared with compound (2) which appeared at $3251 \mathrm{~cm}^{-1}$.

UV spectra of compounds (3a-h) showed bathochromic shift in $\lambda \max (258-288) \mathrm{nm}$ as compared with compound (2) $(\lambda \max 254 \mathrm{~nm})$ due to the conjugation effect and intramolecular hydrogen bonding effect on the electronic transition $\left(\mathrm{n} \longrightarrow \pi^{*}\right)$ in the synthesized compounds $(3 \mathrm{a}-\mathrm{h})$ as shown in Table (1). 
Table (1): physical and spectroscopic data of compound (3a-h).

\begin{tabular}{|c|c|c|c|c|c|c|c|}
\hline \multirow{2}{*}{$\begin{array}{c}\text { Comp. } \\
\text { No. }\end{array}$} & \multirow{2}{*}{$\begin{array}{c}\text { Yield } \\
\%\end{array}$} & \multirow{2}{*}{$\underset{{ }^{\circ} \mathrm{C}}{\mathrm{m} . \mathrm{p} .}$} & \multicolumn{4}{|c|}{ IR. $(\mathrm{KBr}) v \mathrm{~cm}^{-1}$} & \multirow{2}{*}{$\begin{array}{c}\text { UV } \\
(\mathrm{EtOH}) \\
\lambda \max .(\mathrm{nm})\end{array}$} \\
\hline & & & $\begin{array}{c}\mathrm{C}=\mathrm{O} \\
\text { (s) }\end{array}$ & $\begin{array}{c}\mathrm{C} \equiv \mathrm{C} \\
(\mathrm{w})\end{array}$ & $\mathrm{C} \frac{-\cdots}{(\mathrm{s})} \mathrm{C}$ & $\begin{array}{l}\mathrm{O}-\mathrm{H} \\
\text { (br) }\end{array}$ & \\
\hline $3 a$ & 35 & $154-156$ & 1685 & 2140 & $\begin{array}{c}1603 \\
1513\end{array}$ & 3434 & 258 \\
\hline $3 b$ & 38 & $146-148$ & 1686 & 2128 & $\begin{array}{l}1601 \\
1511 \\
\end{array}$ & 3411 & 264 \\
\hline $3 c$ & 25 & $120-122$ & 1682 & 2123 & $\begin{array}{l}1613 \\
1590 \\
\end{array}$ & 3422 & 288 \\
\hline $3 d$ & 41 & $132-134$ & 1684 & 2132 & $\begin{array}{l}1605 \\
1580\end{array}$ & 3416 & 272 \\
\hline $3 e$ & 25 & $91-93$ & 1693 & 2154 & $\begin{array}{l}1615 \\
1524\end{array}$ & 3382 & 262 \\
\hline $3 f$ & 30 & $285-288$ & 1677 & 3130 & $\begin{array}{l}1613 \\
1583\end{array}$ & 3422 & 285 \\
\hline $3 g$ & 50 & $\geq 300$ & 1678 & 2125 & $\begin{array}{l}16) \leqslant \\
1585\end{array}$ & 3425 & 266 \\
\hline $3 \mathrm{~h}$ & & gum & 1678 & 2152 & $\begin{array}{l}1597 \\
1585\end{array}$ & 3382 & 262 \\
\hline
\end{tabular}

Note: The ketonic carbonyl group in compound (3e) was overlapped at $1693 \mathrm{~cm}^{-1}$.

\section{REFERENCES}

1) C. Mannich, W. Krosche. Archiv der Pharmazie, 647-667, 250, 1912.

2) B. Karlen, B. Lindeke, S. Lindgren, K-G. Sevensson and R. Dahlbom, J. Med. Chem. 651, 13, 1970.

3) Chunmei Wei and Chao-Jun Li, J.Am. Chem. Soc. 9584, 125(32), 2003.

4) Afaf H. El-masry, H. H. Fahmy and S. H. Ali Abdel-Wahed, Molecules, 1429, 5, 2000.

5) R. Dahlbom, B. Hannson and R. Mollberg, Acta. Chem. Scand., 2354, 1(8), 1963. Chem. Abs. 9191, 60, 1964.

6) A. Wilson, H. O. Sclhd and W. Modell, "Applied Pharmacology", Churchill livingstone, $11^{\text {th }}$ ed., 133, 1975.

7) Z. Muhi - Eldeen, H. Ghantous and M. Garabet, Iraqi J. Sci., 155, 22(2), 1981. 
8) Z. Muhi - Eldeen, A. Subber, N. Musa and A. Khayat, Eur. J. Med. Chem., 49, 17, 1982.

9) T. R. Jones, M. J. Smithers, R. F. Betteridge and M. A. Taylor, J. Med. Chem., 1114, 29, 1986.

10) (a)- A. H. Khuthier and F. T. Al-Abachi, Iraqi Patent, 2511, 1993.

(b)- Sh. Y. Mahmood, University of Mosul, M. Sc. Thesis, 1997.

11) M. A. Sheat, J. Ed. Sci., 14(4), 51, 2002.

12) (a)- M. A. Sheat and A. A. Dawood, Raf. Jour. Sci., 44, 15(2), 2004. (b)- M. A. Sheat and A. A. Dawood, J. Edu. Sci., 9, 16(2), 2004. (c)- M. A. Sheat and Z. F. Saeed, Nat. J. of Chem., 53, 21, 2006.

13) V. M. Parikh, "Absorption Spectroscopy of Organic Molecules", ترجمة: عبد العسينشربة، جلم الراوي،محمد العراقي،مديرية مطبع هة الجلمع ة،

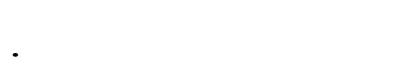

14) N. D. Cheronis and J. B. Entrikin "Identification of Organic Compounds".

ترجمة:موفقشندالة، روعة غيلث الين و نزار الجبور، مديري ـة دار الكت ـب للطباء ـة و

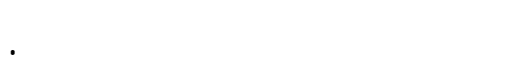

